\title{
Kant On Animal Minds
}

\author{
NAOMI FISHER \\ Clark University
}

\begin{abstract}
Kant's Critical philosophy seems to leave very little room to account for the mental lives of animals, since the understanding, which animals lack, is required for experience and cognition. While Kant does not regard animals as Cartesian machines, he leaves them few resources for getting around in the world in a coherent and responsive way. In this paper I present Kant's account of animal minds. According to this picture, animals have representations of which they are not conscious, and these representations can give rise to inclinations through a form of reflection. While this account faces difficulties in accounting for the variety and complexity of animal behavior, it is impressive in its ingenuity, and it clarifies the role of various faculties and terms in the Critical philosophy.
\end{abstract}

\section{Introduction}

One Kantian insight that has been a major influence both in philosophy and other academic disciplines is that concepts and beliefs are a central factor in determining the way we experience. This insight must be tempered with the fact that there are animals ${ }^{1}$ which have no discursive thought and thus (in the Kantian sense) lack concepts and are incapable of forming judgments, and yet these animals also perceive a world and act coherently in it. When we look at this issue in Kant's own work, the question becomes: Can Kant, one of whose central claims is that the concepts of the understanding are necessary for the possibility of experience, account for the existence of animals as non-rational, perceiving, active beings?

1. I am using the term 'animal' throughout the paper as shorthand for 'non-rational animal'. I do not mean to imply that humans are not animals, nor am I interested in debating the extent to which animals like dolphins or apes are rational (thus possibly falling under some aspects of Kant's Critical treatment of rational minds). Therefore I take as my paradigmatic non-rational animals those with middling mental capacities, for example, cats and chickens rather than aphids or orcas.

Contact: Naomi Fisher <NFisher@clarku.edu > 
While Kant mentions animals only sporadically, what emerges from these various comments is surprisingly coherent. He rejects the Cartesian account of animals as machines (KU 5:464n). ${ }^{2}$ But as is clear from the first sentence of the Anthropology, animals have no ' $\mathrm{I}$ ', no unity of apperception, and no consciousness (Anth 7:127; LM 28:276). Furthermore, animals have no understanding, and so cannot cognize objects (Logik 9:64-5) ${ }^{3}$ and they have no concepts (Logik 24:702), since the understanding is the faculty for the use of concepts. Moreover, they lack the capacity to make judgments; for example, since it lacks "the higher cognitive faculty" of the understanding, the ox cannot judge that the door belongs to the stable (FS 2:59). ${ }^{4}$ Because the understanding is that which takes the material from the senses and synthesizes this material into objective, conscious cognition, animals with no understanding are limited to the material from the senses. ${ }^{5}$

Thus animals are left with meager resources indeed. Kant writes that animals can reflect (KU 20:211), and that they have reproductive imagination ( $L M$ 28:277). Kant attributes to animals a faculty of desire, and also refers to "animal choice" (arbitrium brutum), but that choice is fully determined by their inclinations (MM 6:213). They have sensibility (Anth 7:196), but experience (in Kant's technical sense) is impossible for non-rational animals, since the understanding

2. See Naragon (1990), McLear (2011; 2015), and Hoffmann (2012). I concur with Naragon's treatment in most of what follows, but differ on the issue of animal consciousness. Unlike Naragon (1990), McLear (2011), and Hoffmann (2012), I maintain that Kant is terminologically consistent and sincere in his denial of consciousness to animals, since Kant uses consciousness [Bewusstsein] to mean unified consciousness. Like McLear (2011; 2015), I argue that the mental life of animals is disunified.

3. Here Kant asserts that animals are acquainted with objects-they can compare them in some way - but they do not cognize them. See Section 5 for a discussion of the manner in which animals can differentiate or compare objects without concepts.

4. For further discussion of this (pre-Critical) passage of the ox and the door and its implications for animal perception, see Allais (2009: 406), Hanna (2005: 262). Both argue-in part on the basis of this passage - that it is possible to have intuitions without concepts, since the ox has a representation of the stall and the door. These discussions ignore the context of the passage, in which Kant is scorning Meier's view that animals have clear representations and thus distinct concepts. Also, they do not address the passage immediately following, in which Kant attributes to animals a merely behavioral form of differentiating objects, rather than a logical one. This latter passage problematizes the sense in which the ox has a representation of its stall, particularly a clear one. See Section 5 for a discussion of this passage.

5. Whether animals can have something like intuitions (most importantly, whether their sensing takes place in a spatio-temporal manifold) will depend on whether one believes that the manifold is synthesized into intuitions according to concepts. This is outside the scope of this paper, but a charitable reading of Kant would not attribute a strong conceptualist position to him such that intuitions would be impossible for animals and small children. See Allais (2009: 396-398), who argues that synthesis of a manifold into intuitions (i.e., singular representations) can take place apart from concepts. For a conceptualist position which may also be friendly to the possibility of intuitions without clear concepts, see Grüne (2009). 
is what orders representations according to a priori rules and makes experience possible. So the question now becomes, if a being has only these resources, but no conscious experience, how can it manage to find its way around in the world?

Answering this question is beneficial in two ways: First, it clarifies various concepts and their interrelations in the Critical philosophy, among them representation, reflection, and consciousness. In looking closer at what animals can do with the faculties they possess, we can more clearly understand the import of those various faculties. Second, those who subscribe to a Kantian picture of the role of concepts in experience need to be able to give an account of animals as responsive, aware beings that do not have concepts - and what better place to look for inspiration than Kant's own account of the mental lives of animals?

In the course of this paper, I will show how animals manage, according to Kant, with the faculties attributed to them. Ultimately, through this focused discussion of the mental lives of animals, we can see how it is that Kant can deny consciousness to animals while maintaining that animals are responsive to their environments in a productive and coherent way. Rather than consciousness, Kant attributes to animals a kind of awareness that is disunified. ${ }^{6}$ That animal awareness is disunified and does not rise to the level of consciousness coheres with Kant's attribution of unconscious representations-termed 'obscure representations' - to animals. These representations trigger the appropriate response in the animal. Animals have the capability to reflect on these obscure representations, but animal reflection does not determine concepts. Rather, animal reflection on representations determines inclinations, which in turn trigger the activity of the animal. I will lay out this account in detail below.

We can begin this discussion by looking at what mental tools animals do have: to begin with, the representations provided by the sensibility.

\section{Animals and Obscure Representations}

While he denies that animals have an understanding, or any kind of consciousness or cognition, Kant consistently claims that animals do have something like representations:

The irrational animal $<$ perhaps $>7$ has something similar to what we call representations (because it has effects that are $<$ very $>$ similar to the representations in the human beings) but which may perhaps be entirely different - but no cognition of things; for this requires understanding, a

6. See Footnote 1o below.

7. These $(<>)$ indicate that someone crossed out the word in Kant's original Handschrift. 
faculty of representation with consciousness of action whereby the representations relate to a given object and this relation may be thought. (Anth 7:141n, unpublished; appears only in Handschrift)

What Kant means by "something similar" to representations can be spelled out in his attribution of "obscure representations" [dunkele Vorstellungen] to animals (Anth 7:135). Obscure representations are representations of which we are not conscious, ${ }^{8}$ but we are somehow aware of them nonetheless. This would resolve the tension between Kant's attribution of representations to animals and his denial that they are conscious. ${ }^{9}$

One of Kant's examples of obscure representation is that of the features of a human at a distance that lead us to conclude that this is, in fact, a human being. We are not directly conscious of all the physical characteristics that lead us to this conclusion, but we must be aware of them (indirectly or obscurely) in order to reach the conclusion. This 'awareness' would be operative anytime we make a judgment that an object is of a kind without explicitly or consciously identifying the markers which signal to us what that object is; Kant also uses the example of recognizing an object as a house (Logik 9:34). Moreover, the above quotation implies that while obscure representations may relate to an object, that relation is inaccessible to the understanding if the representation is obscure. We thus may not be able to articulate what it is about a figure that makes us recognize it as human, but those elements are nevertheless present to the mind.

It is not immediately clear what is the meaning of the contrast between representations of which we are conscious and obscure representations. Consciousness of representations appears to go hand-in-hand with cognition of objects. That is, when we bring something under a concept and thereby cognize it as that type of thing, we are directly conscious of it. Obscure representations, on the other hand, can only be perceived "in his [the human's] passive side as a play of sensations" (Anth 7:136). So in conscious representation, the understanding is active with respect to a given object, and brings that object under a concept; in

8. "Obscure representations are those of which one is not conscious" (Lectures on Anthropology 25:479). Kant cannot possibly mean that one is not somehow aware of these representations: the material must be present to the mind in some sense, as is clear from the examples he uses (reading, playing music, judging a person favorably because they are well-dressed, and so on).

9. See, e.g., $L M$ 29:1033. These lecture notes attribute to Kant the view that a lack of consciousness of representations implies animality. He calls Leibniz's slumbering monads, which have no consciousness of their representations, "brute": "[Some monads] were to be considered as slumbering ... i.e., either having no current consciousness at all of their representations, or at least not a consciousness of the manifold in things, therefore not being able to produce any cognition for themselves then because they were not in the condition to separate, to connect, to compare representations, and [he] dismissed them as brute $<$ bruta $>$. Mr. Kant calls this division [of beings] brute mirrors <specula bruta $>$ in contrast to the rational mirrors, rational beings <rationalia>." On the ability to compare representations, see also Section 5 below. 
obscure representations, the understanding does not act on the raw material of sensation, but the material is still present to the mind, though the mind is passive with respect to it. There is an awareness of, although not attention to, obscure representations. This awareness, however, does not rise to the level of consciousness. ${ }^{10}$ I maintain that Kant's attribution of representation to animals should be understood as attributing only obscure representations to animals, representations of which the animal is not conscious. ${ }^{11}$

One question, given this interpretation, is whether obscure representations can count as representations of something, although that judgment is never made explicit or brought to consciousness. As in the example above, when we see a human figure and recognize it as human, certainly those parts of the figure are recognized as parts of a human figure. Although I may not conclude that the man standing in front of me has arms, I am still aware of his arms. If it were to become important that I remember that he has arms, I would certainly be able to do so. We could say that the material of obscure representations is available to but not cognized by the understanding, but this is no help in the case of animals, who have no understanding. The answer for the human case must simply be that although one is not conscious of the representation, one can nevertheless be aware of it as appropriate and relevant to a given concept. Thus, Kant often states that one can be mediately conscious of obscure representations through their relation to a clear (conceptualized) representation: in the above example, the representation of a human, judged as such (Anth 7:135; cf. A728-9/B756-7). In the animal case, there may be an analogous role for obscure representations, one that does not require concepts, but nevertheless relies on the relevance and appropriateness of the representation. We may thus provisionally claim that obscure representation is appropriate and relevant to something non-conceptual in the animal. We will see below (in Section 3) that this is the case.

Kant's other example of obscure representations involves an organist using all of her limbs to play the organ while engaging in a conversation. So the organist's attention is not directed at the music-she is not conscious of it - but she is never-

10. 'Awareness' is my own term; the German Bewusstsein, most often translated 'consciousness', can also be translated as 'awareness'. Thus I do not mean to be tracking Kant's own terminology with this term, but rather introducing a term to capture this having of a representation, and so it being phenomenally in the mind, which does not rise to Bewusstsein of it, in Kant's own terms. I will discuss this issue further in Sections 4 and 5 below.

11. Here I differ from McLear (2011), who claims that not all animal representation is obscure. Grüne (2009: 71-81) has a helpful discussion of obscurity in representations, and its relation to clarity and distinctness. In this monograph, Grüne argues that obscure concepts work to synthesize the material of sensibility into empirical intuitions. While such a model might apply to humans, it is not obviously helpful in the case of animals, whose lack of conceptual capacities would mean that they do not have obscure concepts. As Grüne's treatment shows, the having of obscure representations does not straightforwardly imply anything regarding obscure concepts (2009: 97-102). 
theless producing the piece. One might say she hears the music as she produces it, but she is not listening to it. She may absentmindedly begin a piece without bringing to mind what piece she is playing. Indeed, Kant's example is of an organist playing a fantasy, an improvisational piece. What this example makes clear is that the obscure representations involved in the organist's absentminded improvisation and hearing of her music are not detached from her action, since she is moving her hands and feet based on what she is (obscurely) hearing. Thus the absence of the activity of the understanding can coexist with a kind of activity. Animals can perhaps act in a similar way, that is, thoughtlessly, although not incoherently.

Let us now put this discussion of obscure representation to the side-I will return to it below - and focus our attention on this thought: that although an animal is never conscious of these representations, obscure representations may produce or trigger the actions of an animal. Since animals cannot make judgments about their surroundings, there must be some other mechanism that takes the obscure representation and produces an action. This is the role Kant ascribes to reflection in animals. In the following section, I will lay out how reflection works in this context: according to Kant, "instinctively".

\section{Reflection without Concepts}

Kant's discussions of animal behavior revolve around instinct as that which takes the material from sensibility and produces an action. He claims that animals "can manage provisionally" with sensibility by "following implanted instincts, like people without a sovereign" (Anth 7:196). Instinct is "that voice of God which all animals obey" (Conj 8:111). Animals, unlike humans, are necessitated in their movement by stimuli (or objects of the senses which impel our choices). Consider this passage from the LI Lectures on Metaphysics: ${ }^{12}$

With all non-rational animals the stimuli <stimuli> have necessitating power <vim necessitantem $>$, but with human beings the stimuli <stimuli $>$ do not have necessitating power $<$ vim necessitantem $>$, but rather only impelling <impellentem $>$... . The sensitive power of [free] choice <arbitrium sensitivum [liberum] $>$ is only affected or impelled by the stimuli <stimulis $>$, but the brute one $<$ brutum $>$ is necessitated. (LM 28:255)

Kant goes on to explain that humans are free and can withstand the impelling power of stimuli by acting according to motives of the understanding. Animals

12. While this passage is pre-Critical (ca. 1778-1781), Kant's views remain the same in the Critical period. See A534/B562 and LM 29:896 (Mrongovius, from 1782/3). 
are necessitated and thus not free, but still Kant attributes to them a sensitive power of choice [arbitrium sensitivum brutum]. This presumably means their actions can be attributed to them ${ }^{13}$ - they are not machines - but could not possibly mean that they can choose between various stimuli. In other words, they cannot act according to, or ever in view of, motives of the understanding, which is freedom proper, and, moreover, the material of the sensibility necessitates their actions, such that they could not choose to do otherwise. ${ }^{14}$

But how does instinct operate on the material of the sensibility and give rise to action? Or, rather, what is instinct, and how does it give rise to action? Often we use this word only as a vague placeholder for the ability to act in a coherent way for the material good of oneself or one's species without a thoughtful kind of intentionality. Since the term 'instinct' lacks explanatory content, there should be some way of spelling out how animals can act without understanding that does not rely on this notion of instinct, but rather delves deeper into the mechanisms of animal action. ${ }^{15}$ Kant offers something like this in the first Introduction to the Critique of the Power of Judgement. Like humans, animals reflect. However, this reflection does not determine concepts, but inclinations: "Reflecting ... goes on even in animals, although only instinctively, namely not in relation to a concept which is thereby to be attained but rather in relation to some inclination which is thereby to be determined" (KU 20:211). So when rational beings reflect on the material of the sensibility, they determine a concept that contains those representations upon which they are reflecting. Animals, on the other hand, reflect on their representations and determine some inclination for the objects on

13. Since animals lack autonomy and the ability to do otherwise, this attribution cannot amount to a moral imputability.

14. This interpretation of this passage is based on an account of freedom according to which actions are free only insofar as they are (or, at least, could be) based on motives of the understanding that can overpower sensible stimuli. Just as Kant could say that human actions are imputable when compelled by stimuli, merely in the sense that they are theirs, in such a way animal movements are also imputable. Unlike rational beings, however, animals do not have the option of acting otherwise than they do (since they cannot act according to motives of the understanding) and so are not free in any meaningful sense. Wood argues that this is too restrictive an account, since animals appear to be practically free, or at least undetermined in their actions in a way that machines are not. See Wood (2007: 125-127).

15. See Frierson (2014: 66-72) for a thorough exploration of instinct and its relation to inclination. I differ slightly with Frierson: He claims instincts and inclinations are two different modes by which desire is produced in response to sensory stimuli. I argue here that instinct is one way that inclinations are produced, i.e., without consciousness. There is further work to be done on how pleasure/displeasure and desire fit into this picture for animals. Frierson claims his interpretation applies to animals as well as humans (e.g., 2014: 56 Footnote 10). However, Frierson uses and interprets Kant's usages of cognition - as giving rise to feeling, desire, and inclination - liberally, but since, strictly speaking, animals have no cognition (Logik 9:64-65), it remains a question whether animals would fit easily into Frierson's account, i.e., whether obscure representations in animals produce desire for an object in the same way. 
which they are reflecting. ${ }^{16}$ This inclination may be acted upon, or (presumably) it could be overpowered by a stronger inclination for some other object, which inclination would also be determined reflectively.

But inclinations are certainly not all of the same type. An animal does not simply have an inclination for an object, it must have an inclination for behaving in a certain way with respect to the object. It must have an inclination for the object as a certain type of object: as food, as a plaything, as a potential mate, and so on. If all inclinations were of the same type, it is difficult to see how a wide variety of actions (e.g., eating, playing, mating) could result from inclinations. In the above discussion of obscure representations, we were left with the provisional claim that an obscure representation can become appropriate and relevant to something in the animal, just as it can be appropriate and relevant to a concept in human cognition. The question now is, what is it that obscure representations are appropriate and relevant to, such that animals can be appropriately responsive to objects, without attributing concepts to them? If we allow that the responsiveness of animals is rule-following, then the puzzle about obscure representations can be solved, but in different ways for rational and non-rational sensible beings.

'Appropriateness' is not a well-developed term for Kant, and he only uses it once in this context, ${ }^{17}$ but it turns out to be just the right way of describing the obscure representation both for rational humans and non-rational animals. In the example above of my cognition of a human figure, I cognize the object as human, but the many components of that object remain obscure. However, I can be aware of those features as appropriate to the concept of the object I am cognizing without cognizing those individual features. In the example of the organist, she is aware of the appropriateness of the sounds she hears to the concept of the piece that she is playing while neither thoughtfully attending to nor cognizing those notes: ${ }^{18}$ Only a mistake would draw her attention to her representations of the sound.

Similarly, with animals, if we allow that inclinations are of a certain type, that is, not just for objects but for actions on those objects - to eat, possess, or mate

16. One might wonder how animals can reflect if they lack inner sense or the ability to examine their representations (see Section 5 below for a discussion of this). But reflection need not imply a conscious examination of one's internal states. What holds both in the human case of reflection and is analogous to the animal case is that one is proceeding from the particular instance to a universal rule. In the human case, one might be reflecting to determine a concept; in the animal case, the animal reflects and determines an inclination. Both instances move from particular to general, and both are rule-following.

17. In the example of the musician, Kant uses the terminology of "appropriateness" [Schicklichkeit] to describe the notes that the organist is absentmindedly producing, and he states that "a single stroke of the finger not in accordance with the harmony would immediately be heard [i.e., brought to consciousness] as discordant sound" (Anth 7:136). 
with that object - then obscure representations are appropriate and relevant, not to a concept, but to a given inclination:

Now what occurs on the side of sensibility is that the stimuli <stimuli> so far as they are in conformity with obscure representations, are called instincts, e.g. one has an instinct to eat. (LM 28:256)

As long, then, as the obscure representations are in conformity with or appropriate to the inclination or stimulus, the animal will act. So an animal need not bring an object under the concept of food in order to develop the inclination to eat it. Instead, the animal has an obscure representation of the food. Reflection, then operating "instinctually" and according to rules without the awareness of the animal, picks out that representation as relevant and appropriate for an inclination to eat, and that inclination to eat that object is determined (or produced), which gives rise to the action in the animal. Kant is clear that such a process does not involve concepts, since the rules of reflection guide animals not in conceptualization, but merely in the production of inclinations of various types (KU 20:211).

This way of regarding animal reflection is supported by the following passage from the Anthropology, in which Kant contrasts the rules of the understanding with those of instinct:

the rules [of the understanding] are not to be understood as those according to which nature guides the human being in his conduct, as occurs with animals which are driven by merely natural instinct, but only those that he himself makes. What he merely learns, and thus entrusts to his memory, he performs only mechanically ... and without understanding. (Anth 7:196)

So Kant allows that there are rules that guide animals ${ }^{19}$ in their conduct, somewhat akin to the rules of the understanding. These rules, instead of bringing an object under a given concept, could be understood as bringing an object under a certain kind of inclination. Thus when an animal confronts an object, for ex-

18. This is complicated by the fact that Kant's own example is of an improvisational piece, and so the sense in which there is a concept of the music is difficult to determine. Interestingly, the disharmony of a note would be what brings the music to the attention of the organist, and so it is the harmony of the obscure representations which keeps them below the level of consciousness. And so this example draws the human and animal cases closer together: the organist and the animal both act coherently without direct consciousness of what they are doing. For an insightful discussion of this example, see Kneller (2008: 154-158).

19. Rules of instinct also sometimes guide humans in their behavior; see Anth 7:197 and UH $8: 17$ 
ample, some food, the inclination that is thereby produced is not only for the object, but is for the object as to-be-eaten.

In addition to reflection, Kant also attributes to animals reproductive imagination ( $L M$ 28:277), the non-spontaneous element of the imagination "whose synthesis is subject solely to empirical laws, namely those of association" (B152). ${ }^{20} \mathrm{In}$ other words, animals can develop associations of objects, perhaps by a process of conditioning, but they cannot recognize these associations as lawful (A766-7/ B794-5). However, by "reproductive imagination" Kant cannot mean that the animal engages in a kind of mental comparison of representations, since unity of consciousness is required for such a comparison. ${ }^{21}$ Moreover, Kant claims that without unity of consciousness "all reproduction in the series of representations would be in vain" (A103). Kant is here talking about reproduction in the human case. And so however reproductive imagination operates in an animal, we can expect it to differ significantly from human reproductive imagination, if it is not entirely "in vain".

The above discussion on animal reflection can help to shed light on the function of reproductive imagination in animals. For Kant, reflecting is "comparing a cognition with the power of cognition from which is it supposed to arise (sensibility or the understanding)" (Jäsche Logic 9:76). He also discusses reflection in the context of concept formation: In reflection one cognizes what many things have in common (Vienna Logic 24:909; KU 20:210-213). Animals do none of these things, since they have no understanding, and therefore no concepts. But if they do form associations through reproductive imagination, then instead of taking up a given perception and comparing it to the laws of the understanding in order to identify the object and perhaps modify the concept, an animal's representation could trigger an association produced by the reproductive imagination, and determine an inclination. If an animal's inclinations are thwarted, perhaps this could lead to a modification in the association. According to Kant, the inclination-determining rules (of instinct) are analogous to the rules of the understanding. Thus the reproductive imagination could be that which functions to influence those rules when the animal behavior adjusts in response to its environment, although, given Kant's framework, this would take place without mentally comparing representations. Kant does not say much more about how this faculty would operate in animals, but at least here there is a possible way forward in accounting for learned behavior in animals.

20. See Frierson (2014: 97-99) on the causal role of the imagination in association and connection of sensory cognitions.

21. See Section 5 below for a discussion of comparison of representations. 


\section{Awareness without Unity}

Kant says in several places that animals "are entirely lacking in consciousness" and calls instinct "the faculty for performing actions without consciousness" ( $L M$ 28:690; cf. $L M$ 28:276). Several recent papers have claimed that Kant could only mean that they have no self-consciousness, and could not possibly mean that they are not conscious at all, since they have representations and this implies consciousness. ${ }^{22}$ There are difficulties with this interpretive move, however, since according to many interpretations of the transcendental deduction, Kant's argument hinges on the claim that consciousness implies self-consciousness. ${ }^{23}$ Animals would be a counterexample to this claim since, according to common understanding, they must be conscious (since they have representations) and yet they are not self-conscious. Rather than interpret Kant as denying consciousness to animals, both Naragon (1990) and McLear (2011) argue that many claims that Kant makes denying consciousness to animals arise from the various ways Kant uses the word 'consciousness' [Bewusstsein]: Sometimes he uses it in a robust sense, to mean self-consciousness, and sometimes he appears to use it in a much more minimal sense, to mean awareness of any kind. ${ }^{24}$ Thus Kant attributes to animals a low-level consciousness (consciousness in the latter sense) that does not imply self-consciousness.

While both are right in ascribing to Kant the view that animals have some very minimal form of awareness, I maintain that Kant is not as loose in his language as these interpretations imply. When Kant uses the term 'consciousness', he almost always is using it in the context of human consciousness, and he means a unified consciousness. It is worth noting that this is in tension with how we understand the term, that is, as any kind of phenomenal awareness. Unified consciousness, by itself, is not self-consciousness, but it does imply self-consciousness in rational beings, as Kant shows in the transcendental deduction. (We should, however, be wary of taking his conclusions and applying them in other domains, specifically in the domain of non-rational beings, for whom the transcendental deduction may have no import at all). But when Kant uses the term 'empirical

22. See Naragon (1990) and McLear (2011).

23. Not all interpretations of the transcendental deduction have Kant making this rather strong claim. If one takes the starting point of the transcendental deduction to be ordinary empirical knowledge rather than any kind of consciousness at all, then the results of the transcendental deduction would be much more limited in scope and would not apply at all to animals. See Ameriks (2003: 5-22, 51-66).

24. "Thus, Kant's denial of consciousness to animals in (10), I argue, extends only to the denial of self-consciousness (i.e. the representation of an 'I') rather than the denial of POV or phenomenal consciousness" (McLear 2011: 9). See also Hoffmann (2012: 136-138), who agrees that Bewusstsein is used in various ways, and so Kant's denial of consciousness to animals ought not be taken strictly. 
consciousness', he means awareness that it not unified. At B131-133 he speaks of empirical consciousness as not having any relation by itself to the identity of the subject. He also discusses this notion in a note at A117: He states, "All empirical consciousness, however, has a necessary relation to transcendental consciousness ... . It is therefore absolutely necessary . . . that all consciousness belong to one consciousness." At first glance, this passage might seem to imply that all disconnected empirical consciousness is necessarily unified. But Kant is simply discussing human empirical consciousness, which would have a necessary relation to transcendental consciousness. Empirical consciousness is used to signify that which is not unified, that which is originally episodic and disunified, ${ }^{25}$ and which comes to be unified in a transcendental consciousness. ${ }^{26}$

McLear maintains that animal awareness consists of a fragmentary awareness of individual representations, as described above. ${ }^{27}$ I agree with this conclusion; indeed, it is strengthened by the terminological understanding I have just presented. Whenever Kant claims that animals have no consciousness, he does not just mean that they have no self-consciousness, as McLear claims, but rather he means that they have no unified consciousness; that their awareness of representations is disconnected, as in the description of empirical consciousness above. In his discussions of empirical consciousness Kant is speaking of a philosophical possibility (that is, how consciousness comes to be unified in rational beings). Yet, we can extend this notion of empirical consciousness to something that actually occurs in non-rational animals. Empirical consciousness without transcendental consciousness would not be mentally unified; the awareness would be disconnected and episodic. Perhaps some kind of unity could be salvaged by attributing these states to a physical organism that persists through time, but this unity would not be mentally available to the organism at all. I will call this 'empirical awareness' to distinguish it from human empirical consciousness.

Several passages in which Kant specifically discusses animals imply that their awareness is minimal and disconnected in this very way. ${ }^{28}$ Also, in the following passage, Kant describes what awareness without consciousness (in the robust unified sense of the word) would be like in humans:

25. McLear (2015: 98-100) also uses the term 'episodic' to describe animal awareness.

26. Cf. Hoffmann (2012: 70-71).

27. McLear (2011: 11; 2015: 98-100). My disagreement with McLear here is primarily terminological, but it relates to the nature of consciousness. I maintain that in order to be conscious of a representation, an animal must have unified consciousness. From another angle: What McLear calls "aesthetic unity" cannot amount to consciousness of a representation in an animal, since this requires discursive unity, which animals clearly lack.

28. See in particular LM 28:276-277: "[Animals] will have no general cognition through reflection, no identity of the representations, also no connections of the representations according to subject and predicate, according to ground and consequence, according to the whole and according to the parts; for those are all consequences of the consciousness which animals lack." 
Without consciousness that which we think is the very same as what we thought a moment before, all reproduction in the series of representations would be in vain. For it would be a new representation in our current state, which would not belong at all to the act through which it had been gradually generated, and its manifold would never constitute a whole, since it would lack the unity that only consciousness can obtain for it. (A103)

Kant, then, allows for the theoretical possibility of representations that are not unified specifically when discussing what representations would be like without consciousness. Thus the above description can be regarded as a description of animal awareness. In fact, in a 1789 letter to Marcus Herz, Kant mentions animals when discussing how it would be impossible for someone to have knowledge apart from the conditions of the understanding. He states that without the understanding, sense data "would never ... represent objects. They would not even reach that unity of consciousness which is necessary for knowledge of myself (as an object of inner sense)." He goes on to say:

They [i.e., sense data] could still (if I imagine myself to be an animal) carry on their play in an orderly fashion, as representations connected according to empirical laws of association, and thus even have an influence on my feeling and desire, unconscious of my existence [meines Daseins unbewusst] (assuming that I am even conscious [bewusst] of each individual representation, but not of their relation to the unity of representation of their object, by means of the synthetic unity of apperception). This might be so without my knowing the slightest thing thereby, not even what my own condition is. (Correspondence, Letter to Marcus Herz, May $26,1789 ; 11: 52)^{29}$

So his denial that animals have understanding or reason leads inevitably to the conclusion that animals cannot have any connection of representations, but this lack of connection does not preclude these sense data from having an effect on the animal. The lack of consciousness Kant mentions in the above passage should be interpreted as a lack of unified and sustained awareness of the representations, as he specifies: He is unbewusst (unconscious) of his very existence, since his representations are not unified; nevertheless he is bewusst (phenomenally aware, in a disconnected way) of each individual representation. ${ }^{30}$

29. Translation slightly modified where German text is given.

30. Indeed, Kant's parenthetical clarification in the passage makes clear that in the second instance, he is using bewusst in an atypical way which does not imply unity. 


\section{Inner Sense, Consciousness, and Representation}

The claim above that animals cannot take themselves as an object of inner sense further elucidates Kant's position on animals. In his lectures, inner sense is identified with consciousness of representations: "Inner sense is the consciousness of our representations themselves" (LM 29:882, ca. 1782/3). Kant spells out consciousness of representations as follows: "To be conscious of a representation is: to know that one has this representation, i.e.: to distinguish this representation from the other" (RL 1679; 16:80). ${ }^{31}$ Thus, consciousness of representations involves distinguishing representations from each other. Since such distinguishing requires unity of consciousness (A103), it follows that consciousness of representations requires and implies unified consciousness. Inner sense, as stated above, is consciousness of one's representations. Therefore, in inner sense, one is able to make a cognitive distinction between one representation and another in a unified consciousness. In other words, if animals were conscious of their representations (i.e., if their representations were clear rather than obscure), they would have inner sense, unity of consciousness, and the ability to differentiate representations. It follows straightforwardly from this that animals, who lack both inner sense and unity of consciousness, are not conscious of their representations. All of their representations are obscure.

Kant does sometimes attribute to animals the ability to differentiate or compare representations: Animals are acquainted with objects "according to the similarity and the difference" (Logik 9:65) and they "compare representations with one another" (LM 29:888). But it is clear that this comparison is not the logical comparison of representations in consciousness that Kant is discussing in the above quotations, and which he consistently denies to animals (LM 28:276-277; 29:1033; FS 2:60). In the pre-Critical False Subtlety 2:60, Kant claims that animals physically differentiate representations by being driven to different actions by different representations, and he contrasts this differentiation with logical differentiation, which requires cognition of the difference. ${ }^{32}$ While this passage is

31. See also (the pre-Critical) $R L 1678,16: 79-80$ : “Consciousness is a (clear) representation of one's own idea .... Because the soul knows what it represents and how it represents it, so can it handle its representations in various ways: compare, abstract, connect them, and thereby to accomplish that which is called thinking-over [nachdenken]. This the animals cannot do, because they are not conscious of their representations" (translations mine; Reflexionen 1678 and 1679 are dated 1755/6). While these passages are pre-Critical, they indicate how he tends to define or think of the term 'consciousness', i.e., not as awareness of any kind. Already in the pre-Critical period, it is a thicker term involving differentiation of representations.

32. "Physically differentiating means being driven to different actions by different representations. The dog differentiates the roast from the loaf, and it does so because ... the sensations cause by the roast are a ground of desire in the dog which differs from the desire caused by the loaf, according to the natural connection which exists between its drives and its representations" (FS 2:60). 
pre-Critical, it coheres with the account given above of Kant's Critical view of animals, and offers a way of making Kant's Critical statements of animals coherent. How can it be that animals differentiate representations, when such differentiation requires consciousness, which Kant states animals lack? The answer is that animals cannot differentiate representations logically, but merely physically, and this physical differentiation can be spelled out according to the account of animal reflection given in Section 3. This account offers a clear explanation of how animals may be acquainted with objects according to the similarity and difference without conscious comparison of representations: through inclinationdetermining reflection, which will produce different (or similar) responses to different (or similar) obscure representations. 33

This notion of physical differentiation also makes sense of a first Critique footnote in which Kant claims that there is "certain degree of consciousness" even in obscure representation, and that only if there is "consciousness of the difference" is the representation called clear. This "certain degree of consciousness," as I argue above, cannot amount to consciousness proper, which is unified, but is what I have called 'awareness'. Obscure representation can often suffice "for a distinction" (B414-415). Without the notion of physical differentiation, it would be difficult to say what a distinction between representations without consciousness of the difference between those representations could amount to. But here, we have the resources to say that such a distinction amounts to a physical differentiation. Different representations produce differential behaviors - not because there is an awareness of a difference, but simply because there is a difference. Different obscure representations, through animal reflection and the production of inclinations, produce different responses.

Some have argued that Kant must allow that animals are capable of inner sense, if they are capable of empirical consciousness and perception, and so when Kant denies inner sense to animals, he is using the term in a particularly strong way. ${ }^{34}$ This would be right were animals to have empirical consciousness and perception in the same way that rational beings have these capacities, namely, if having representations required that they be available as objects of inner sense to be compared and differentiated. But if my interpretation is correct, then animals have no clear representations, no consciousness of them, and so their representations are not available to them as objects of inner sense which can be compared and differentiated. And so Kant's claims that animals have no inner sense are consistent with his claims that they do have representations.

One might object that if animals have no inner sense, then they cannot have any time determinations, since "time is nothing other than the form of inner

33. Cf. Grüne (2009: 85-88).

34. See Hoffmann (2012: 155-158). McLear (2011) reaches similar conclusions. 
sense" (A33/B49). And, further, if the obscure representations of an animal bear no temporal relationship to each other, from the perspective of that animal, the obscure representation cannot explain an animal's differential reaction to its environment. 35 This objection may be particularly salient for behaviors which are not merely immediate, but are drawn out processes, such as spinning a web, stalking prey, or fleeing from a predator. Nevertheless, a temporal determination is not required for a physical reaction which is sensitive to that representation. An animal may react instantly to some stimulus, a visual field, for instance, with whatever mental machinery is in place at the moment (from our perspective) of that stimulus. Any "learning" behavior may be a result of that stimulus and its aftermath altering the mental capacities of the organism, but it need not be because of some mental differentiating or remembering, per Kant's distinction, discussed above, between logical and physical differentiation. Moreover, for longer processes, as long as that original stimulus gives rise to some ongoing (perhaps adrenal) stimulus, the animal may continue to, for instance, flee. While rational observers experience these events in terms of cause and effect, admitting of temporal description and determinations, the animal need not have such an experience in order to react differently to different stimuli.

And so we see that Kant's claim that animals are not conscious, far from being problematic, in fact fits together quite nicely with his other claims regarding animals, representation, inner sense, consciousness, and reflection. When Kant denies consciousness to animals, he means to deny them unified consciousness: Animals have a low-level awareness (what I've called 'empirical awareness') of their obscure representations that is not unified, and that Kant very rarely uses Bewusstsein and its variations in this minimal sense. ${ }^{36}$ As discussed above, ob-

35. An important, related objection is that if an animal does not order events in time, then it is unclear how their representations are empirical or about the world at all. On this point, $\mathrm{KrV}$ A99 is salient; here Kant claims that although every intuition contains a manifold, it cannot be represented as such without time determinations. "for as contained in one moment no representation can ever be anything other than an absolute unity". If we apply this to animals, it appears that although animals receive the intuitions in succession, they cannot differentiate (logically) the items within that momentary intuition, since they cannot order them in time. This is consistent with what I have argued above. There are further issues to explore here, related to the resultant implication that animals lack a synthesis of apprehension, but such issues are outside the scope of this paper.

36. One exception (in addition to Kant's letter to Markus Herz, discussed above) is a note at B414-B415, in which Kant claims that there is "a certain degree of consciousness" in the case of obscure representations. This would be difficult to square with Kant's definition of obscure representation as representations of which one is not conscious, if we lacked the interpretive framework I have laid out. Here I have made room for a lower form of consciousness as disunified, particularly in the case of obscure representation - such disunified consciousness I call 'awareness' in animals. Here we can interpret "a certain degree of consciousness", not as consciousness proper, which is unified, but as awareness taking place outside of the unity of consciousness. This passage thus indicates that Kant is on board with the idea that obscure representation implies this minimal, ultimately disunified form of awareness. (This raises a further interpretive issue in the human case, 
scure representations in animals, by means of reflection which determines an inclination rather than a concept, trigger the appropriate response. Inner sense, consciousness of representations, the ability to logically differentiate representations, and unity of consciousness all mutually require and imply each other, and all are lacking in animals. Kant's claims that animals lack these mental capacities, when interpreted carefully in the ways that I detail above, are thus consistent and should be regarded as Kant's considered view on animal minds.

\section{Empirical Consciousness and Unity}

But this solution to the problem of animal awareness introduces new problems: If empirical consciousness has a necessary relation to transcendental consciousness for rational beings (A117), how do animals escape this necessity? Moreover, humans also have obscure representations, as discussed above. If such representations are not connected in animal consciousness, there is a danger that these representations may fall outside of the unity of consciousness that humans enjoy, and remain disconnected from the rest of a person's cognitive life, which would be unacceptable. To solve these problems we must delve a bit deeper into how consciousness becomes, or fails to become, unified.

It is worth stressing at this point that a Kantian picture would benefit from an account of how consciousness gradually comes to be unified, since this is certainly what happens in young humans. In offering an account of sub-rational mentality, we thereby point the way to how a Kantian picture might account for the emergence of rational subjectivity in an individual human, or perhaps also in an evolutionary context. This must take account of how the mental capacities of a non-rational sensible being differ from that of a rational human. As I have shown above, a capacity which functions in one way in a rational human may function differently in an animal; reflection is one such capacity, representation is another. And so the account I've offered, while it takes as its basis capacities that animals share with humans, departs from that basis in its independent accounts of representation, reflection, comparison of representations, and so on. This is a benefit of the account, as it offers the possibility of a discussion of the origins of human rational subjectivity in the mental life of a non-rational sensible being, rather than regarding human beings as animals with some capacities tacked on, or animals as human beings with some capacities missing. 37 In this

namely, how an obscure representation can fall outside of the unity of consciousness in a human and yet belong to her; this is addressed below in Section 6).

37. For an opposing view, see Hoffmann (2012: 3-5), who argues that animals must be understood in terms of the features of transcendental subjectivity if they are to be understood at all. Hoffman's insistence on this point results in attributing to animals capacities that they do not have, 
section, and in response to the above problems, I offer a sketch of how such a developmental account of unification of consciousness might proceed.

Kantian apperception unifies consciousness - it is constructive-but it cannot be fully constructive such that the only states included in the self are apperceptive ones, since in that case obscure representations would remain disconnected from and unavailable to consciousness in a rational being. ${ }^{38}$ And so we need a way to connect non-apperceptive states to the unity of consciousness without denying the unifying role that Kant gives to apperception.

Representations, according to Kant, have a necessary relation to a possible empirical consciousness which can be unified in transcendental consciousness (A117n). In humans, then, all representations, whether obscure or clear, are related to an individual possible empirical consciousness. All representations belong to one self-consciousness, not because they are actually unified by that self-consciousness, but because of the potential to be unified: "As my representations (even if I am not conscious of them as such) they must yet necessarily be in accord with the condition under which alone they can stand together in a universal self-consciousness, otherwise they would not throughout belong to me" (B132). In other words, all empirical consciousness is unified, but some representations may be related to a possible empirical consciousness, which might not be unified, but merely unifiable. And therefore the relation of a representation to a possible empirical consciousness does not entail that I am conscious of that representation. In the human case, although I am not conscious of obscure representations, they nevertheless belong to a possible empirically conscious state, and could come to be unified in self-consciousness. They are, in that sense, mine. In animals, who do not have unified consciousness, we could say that their representations - all of which are obscure-have a necessary relation to each individual empirical awareness, which would be relevantly similar to the human "possible empirical consciousness"; in the animal case, however, empirical awareness does not have a necessary relation to transcendental conscious-

particularly, inner sense (see Section 5 above). Once we allow this, I believe Brandt is correct that we are bound to keep going with the conclusions of the first Critique, and animals then cannot be excluded from self-consciousness and other capacities which we know that they, as non-rational beings, do not have. See Brandt (2010: 55-65).

38. See Ameriks (2000: 234-264). Here Ameriks also discusses a non-constructive interpretation, according to which apperception involves taking one's own thought as an object, which proves - contra a kind of Humean skepticism - that there is an underlying unity to the self. We have already seen that animals, according to Kant, do not have a unified consciousness, precisely because they have no understanding and so cannot apperceptively unify their various states. So this "Cartesian" interpretation makes too much of self as an entity which already underlies my various states, and so makes apperception a primarily epistemological phenomenon, which on this view becomes a tool to defeat skepticism. We need, rather, to take seriously both the idea that apperception is constructive and not merely epistemological, since it unifies our various states, and that it cannot be completely constructive, for otherwise it can leave important states out. 
ness. And thus an animal's obscure representations are not unified, and so do not rise to the level of consciousness. Indeed, they cannot be unified, since there is no transcendental consciousness at work in the animal.

The young human and the animal thereby differ in this picture, insofar as the possible empirical consciousness in the human is relatable to a transcendental consciousness, as soon as such a capacity develops. There is no transcendental consciousness that could develop in the animal, and so there is not even a possible relation to a single consciousness which could draw these states together. But in the human case, this modal relation to transcendental consciousness offers a shared property among the various possible states of empirical consciousness, although those states are not unified in thought until they are synthesized into one transcendental consciousness. Not all states are brought into conscious unity, but all states could be brought into conscious unity, and thus all of those states belong to that unified subject as the possible objects of her consciousness. This may provide to Kant one way of accounting for the development of unity in an individual human. Once apperception is in place, consciousness, inner sense, and similar cognitive capacities could develop gradually. Indeed, we might expect consciousness and inner sense to build gradually as the child gradually bestows her conscious attention on more of her representations as her own, thus progressively unifying her disparate possible empirically conscious states in a single consciousness.

Thus, in rational humans, all mental states would belong to the self as unified by transcendental apperception: Although obscure representations would stand outside of conscious unity, they belong to the subject in virtue of their necessary relation to a possible empirically conscious state of the subject. This is in contrast to the animal case, in which there is no mentally unified subject to whom representations could belong. We might say a young child has only possible empirical consciousness, which functions like empirical awareness does in the animal. However, as the child develops, she gradually develops that unity of consciousness as each possible empirical consciousness becomes actual. Nevertheless, most of these states will always remain merely possible and thereby under the level of unified consciousness; this is where the obscure representations of the human being remain.

\section{Conclusion}

Kant's Critical philosophy, which relies so heavily on the unity of apperception, or transcendental self-consciousness, must attribute a very low level of mental activity to non-rational animals. The high bar of intellectual self-consciousness is just not something animals can meet. They are thus relegated to the level of mere 
sensibility, with no unified consciousness and no Kantian experience. However, animals have obscure representations, a disunified empirical awareness, and the ability to reflect on obscure representations, which produces inclinations and coherent behavior. Moreover, we may allow that animals can form associations of objects through the faculty of reproductive imagination, which may give Kant a way of accounting for learned behavior in animals, through the formation and modification of associations of empirical objects.

Nevertheless, animals are completely necessitated in their behavior: They cannot choose between alternative stimuli, nor is their cognitive activity within their control. An obscure representation gives rise to an inclination to act in a particular way, which cannot be resisted. This model of animal mental life and behavior fits well within the Critical philosophy. And so I have gone some way in responding to those who believe that the existence of animals poses insurmountable problems for Kant's Critical philosophy. 39

In denying that animals can have a unified consciousness, Kant makes it difficult to account for the complexity and variety of animal behavior. While the model may fit well with what we know of spiders or ticks, it is less amenable to the behaviors of animals such as wolves or bears or other cognitively advanced mammals, since these animals appear to have memories and emotions associated with those memories. Such animals can be innovative, vengeful, mournful. That such behaviors are the result of built-in machinery that operates without any unity of thought may strike one as implausibly deflationary. Nevertheless, Kant's statements on animals, taken together, constitute a framework which offers viable answers to the difficulty of accounting for animal behavior with such meager resources.

Another difficulty for Kant involves the gradual increase in cognitive abilities that we see both in the animal kingdom and in the development of rationality in an individual human child. Kant has carved out a place for a being with middling mental capacities, but how a being of middling mental capacities could develop gradually into a full-fledged rational human is not immediately clear, especially since experience for Kant seems to be an all-or-nothing phenomenon, which is fully dependent on the possession of an understanding. Above (see Section 6) I give a sketch of how such a gradual account might be accommodated into the Critical philosophy, but such an account could be further elaborated.

Even if Kant's theoretical framework for animal mentality is ultimately re-

39. Reinhard Brandt, for instance, argues that we must take into account the similarities between animals and humans, and once we do so, we cannot exclude them from various conclusions reached in the course of the first Critique, many of which cannot plausibly apply to animals; see Brandt (2010: 55-65). I have argued instead that we can account for such similarities-e.g., the coherent behavioral responses to sensory stimuli-without mental unity, and animals would thereby be excluded from the arguments which presuppose this mental unity. 
garded as unsatisfactory, examining this framework has shed light on other aspects of the Critical philosophy. In particular, we have a clearer picture of how the unique capacities of rational human beings alter the character of our mental lives and distinguish us from other animals.

\section{Acknowledgements}

Many have given me helpful input on this paper or earlier versions of it; I am especially grateful to Karl Ameriks, Babak Bakhtiarynia, Dante Dauksz, Jeffrey Fisher, Fred Rush, Eric Watkins, and participants at the 2015 Midwest Study Group of NAKS, especially Corey Dyck, Alexandra Newton, Jessica Tizzard, Clinton Tolley, and Rachel Zuckert. I am also grateful to several anonymous referees for their helpful suggestions and comments.

\section{Abbreviations}

RL Kant, Immanuel (1914). Handschriftlicher Nachlaß: Logik (Erich Adickes, Ed.). Kants gesammelte Schriften: Vol. 16 (Akademie der Wissenschaften, Ed.). Georg Reimer (later Walter De Gruyter).

MM Kant, Immanuel (1996). Metaphysics of Morals. In Mary Gregor (Ed. and Trans.), Practical Philosophy. Cambridge University Press.

KU Kant, Immanuel (2000). Critique of the Power of Judgment (Paul Guyer and Eric Matthews, Eds. and Trans.). Cambridge University Press.

LM Kant, Immanuel (2001). Lectures on Metaphysics (Karl Ameriks and Steve Naragon, Eds. and Trans.). Cambridge University Press.

Logik Kant, Immanuel (2004). Lectures on Logic (J. Michael Young, Ed. and Trans.). Cambridge University Press.

Anth Kant, Immanuel (2008). Anthropology from a Pragmatic Point of View (Robert Louden, Trans.). In Robert Louden (Ed.), Anthropology, History and Education (227-429). Cambridge University Press.

UH Kant, Immanuel (2008). Idea for a Universal History with a Cosmopolitan Aim (Allen Wood, Trans.). In Robert Louden (Ed.), Anthropology, History and Education (121-142). Cambridge University Press.

\section{References}

Allais, Lucy (2009). Kant, Non-Conceptual Content and the Representation of Space. Journal of the History of Philosophy, 47(3), 383-413. https://doi.org/10.1353/hph.0.0134

Ameriks, Karl (2000). Kant and the Fate of Autonomy: Problems in the Appropriation of the Critical Philosophy. Cambridge University Press. https://doi.org/10.1017/ CBO9781139173346

Ameriks, Karl (2003). Interpreting Kant's Critiques. Clarendon Press. https://doi. org/10.1093/0199247315.001.0001 
Brandt, Reinhold (2010). Immanuel Kant - Was bleibt? Meiner.

Frierson, Patrick (2014). Kant's Empirical Psychology. Cambridge University Press. https:// doi.org/10.1017/CBO9781139507035

Grüne, Stefanie (2009). Blinde Anschauung: Die Rolle von Begriffen in Kants Theorie sinnlicher Synthesis. Vittorio Klostermann.

Hanna, Robert (2005). Kant and Nonconceptual Content. European Journal of Philosophy, 13(2), 247-29o. https://doi.org/10.1111/j.0966-8373.2005.00229.x

Hoffman, Thomas (2012). Zum Problem eines Bewusstseins bei Tieren am Paradigma der kantische Theorie des Bewusstseins (Doctoral Dissertation, Unversität Trier). Retrieved from http://ubt.opus.hbz-nrw.de/volltexte/2012/758/

Kant, Immanuel. (1900-). Kants gesammelte Schriften (Akademie der Wissenschaften, Ed.). Georg Reimer (later Walter De Gruyter).

Kant, Immanuel (1992). The False Subtlety of the Four Syllogistic Figures (David Walford, Trans). In David Walford and Ralf Meerbote (Eds.), Theoretical Philosophy: 17551770 (85-105). Cambridge University Press.

Kant, Immanuel (1999). Critique of Pure Reason (Paul Guyer and Allen Wood, Eds. and Trans.). Cambridge University Press.

Kant, Immanuel (2007). Correspondence (Arnulf Zweig, Trans.). Cambridge University Press.

Kant, Immanuel (2008). On the Use of Teleological Principles in Philosophy (Günther Zöller, Trans.) In Robert Louden (Ed.), Anthropology, History and Education (192-218). Cambridge University Press.

Kant, Immanuel (2012). Lectures on Anthropology (R. Clewis, R. Louden, G. F. Munzel, and A. Wood, Trans.). Cambridge University Press. https://doi.org/10.1017/ CBO9781139028639

Kneller, Jane (2008). Kant and the Power of Imagination. Cambridge University Press.

McLear, Colin (2011). Kant on Animal Consciousness. Philosophers' Imprint, 11(15), 11-16.

McLear, Colin (2015). Two Kinds of Unity in the Critique of Pure Reason. Journal of the History of Philosophy, 53(1), 79-110. https://doi.org/10.1353/hph.2015.0011

Naragon, Steve (1990). Kant on Descartes and the Brutes. Kant-Studien, 81(1), 1-23. https://doi.org/10.1515/kant.1990.81.1.1

Wood, Allen (2007). Kantian Ethics. Cambridge University Press. https://doi.org/10.1017/ CBO9780511809651 